\title{
INTERNACIONALIZAÇÃO DA PÓS-GRADUAÇÃO: O PROGRAMA DE PÓS-GRADUAÇÃO EM DESENVOLVIMENTO REGIONAL - UTFPR
}

\author{
INTERNATIONALIZATION OFGRADUATE: THE POST-GRADUATE \\ REGIONAL DEVELOPMENT- UTFPR
}

\author{
MATTOS, Luciane Maria Serrer \\ lummattos@yahoo.com.br \\ UTFPR - Universidade Tecnológica Federal do Paraná \\ RUBIN-OLIVEIRA, Marlize \\ rubin@utfpr.edu.br \\ UTFPR - Universidade Tecnológica Federal do Paraná
}

\begin{abstract}
RESUMO Este texto apresenta uma reflexão sobre a internacionalização da Educação Superior, enfatizando o Programa de Pós-Graduação em Desenvolvimento Regional da Universidade Tecnológica Federal do Paraná - Campus Pato Branco. O objetivo é analisar a trajetória do Programa no que se refere à internacionalização e, para tanto, apresenta-se um panorama da internacionalização da Educação Superior e uma pesquisa documental a partir dos currículos (lattes) dos professores permanentes do Programa. Além disso, faz-se um levantamento dos estudantes estrangeiros matriculados no Programa desde sua criação. As análises demonstram baixo nível de internacionalização no Programa, fato que já foi percebido pelo corpo docente e que faz parte da Proposta do Programa como um desafio a ser efetivado.
\end{abstract}

PALAVRAS-CHAVES: Ensino Superior. Globalização. Stricto Sensu.

ABSTRACT This paper presents a reflection on the internationalization of higher education, emphasizing the Graduate Program in Regional Development, Federal Technological University of Paraná-Campus Pato Branco. The objective is to analyze the trajectory of the program with regard to internationalization and, therefore, presents an overview of the internationalization of higher education and documentary research from the curriculum (lattes) Program of permanent teachers. Moreover, it is a survey of foreign students enrolled in the program since its inception. Analysis show slow level of internationalization in the program, which has already been noticed by the faculty and is part of the Proposed Program as a challenge to be effected.

KEYWORDS: Higher Education. Globalization. Stricto Sensu.

\section{INTRODUÇÃO}

A internacionalização da Educação Superior é uma temática que vem crescendo ao longo das últimas décadas. Embora nos últimos anos tenha sido expressiva a internacionalização da graduação, esta temática continua sendo ainda 
Atos de Pesquisa em Educação - ISSN 1809-0354

Blumenau - vol. 11, n. 2, p.353-373 ago./nov. 2016

DOI: http://dx.doi.org/10.7867/1809-0354.2016v11n2p353-373

mais intensa na pós-graduação. Isto se justifica, principalmente, pelo papel que a pósgraduação desempenha no âmbito da pesquisa no Brasil.

Goergen (2012) afirma que a universidade, sobretudo a pós-graduação, é a principal responsável pela produção e difusão do conhecimento científico. Por isso, suas atividades de ensino e pesquisa estão envolvidas nas estratégias globais, além de contribuir, ela mesma, para o aprofundamento e consolidação desse processo de internacionalização, na medida em que é um dos pontos centrais do processo internacional de produção e disseminação de conhecimentos.

Para refletir sobre a internacionalização na pós-graduação, o presente texto partiu da experiência que vem sendo construída pelo Programa de Pós-Graduação em Desenvolvimento Regional (PPGDR) da Universidade Tecnológica Federal do Paraná - Campus Pato Branco. Este Programa foi criado em 2009 e se insere na área de Avaliação da Coordenação de Aperfeiçoamento de Pessoal de Nível Superior (CAPES) de Planejamento Urbano e Regional/Demografia.

De acordo com o Documento de Área (CAPES, 2009), a área de avaliação em Planejamento Urbano e Regional/Demografia é composta por subáreas: 1Planejamento Urbano e Regional e 2- Demografia. A primeira subárea teve início na década de $1970 \mathrm{com}$ a finalidade de formar quadros qualificados para a formulação e implementação de políticas urbanas e regionais que o regime militar idealizava. Durante a década de 1980 não foi aberto nenhum novo curso nessa subárea e na década seguinte houve um aumento pouco significativo, ou seja, foram abertos apenas seis programas. Na outra área, foram abertos dois programas em Demografia na década de 1990.

No início dos anos 2000, houve um aumento significativo, especialmente na subárea de Planejamento Urbano e Regional. Houve uma evolução desde o ano de 2001 quando havia oito cursos na subárea de planejamento urbano e regional. Em 2012, a subárea estava composta por 42 cursos num total de 32 programas. Quanto a subárea de Demografia, há atualmente no Brasil 4 programas com 6 cursos (CAPES, 2013).

O Documento de Área (CAPES, 2009) deixa claro que o mais importante do que a expansão quantitativa são as transformações pelas quais a área passou durante esse período. Inicialmente, os cursos localizavam-se nas regiões mais dinâmicas do 
Atos de Pesquisa em Educação - ISSN 1809-0354

Blumenau - vol. 11, n. 2, p.353-373 ago./nov. 2016

DOI: http://dx.doi.org/10.7867/1809-0354.2016v11n2p353-373

país ou em metrópoles regionais mais distantes. Apenas no início dos anos 2000 houve a abertura de cursos fora das áreas metropolitanas ou em áreas que estão mais longe dos principais centros do país, expressando, de acordo com o Comunicado da Área (CAPES, 2012), o crescente reconhecimento dos problemas urbanos e regionais que o país enfrenta e o movimento de expansão da pós-graduação pela via da interiorização (RUBIN; GRIKE, 2012).

Os cursos criados nos anos 2000 trazem a temática do desenvolvimento regional e suas diferentes facetas, representando um grande desafio de reflexão para a área. Desafio esse que também se origina da adoção de abordagens interdisciplinares nas suas atividades de ensino, pesquisa e extensão.

Dentro desse quadro, o Programa de Pós-Graduação em Desenvolvimento Regional (PPGDR) tem como objetivo contribuir com a reflexão e a prática que ocorrem na interface entre sociedade e natureza, através da produção e difusão de conhecimento científico, na perspectiva interdisciplinar. Espera, dessa forma, contribuir com a formação de profissionais capazes de atuar na pesquisa, no ensino e como agentes de desenvolvimento regional em bases sustentáveis (UTFPR, s/d).

A área de concentração do PPGDR é Desenvolvimento Regional Sustentável e orienta-se pelo estudo dos objetos e dinâmicas na interface Sociedade e Natureza. Ou seja, o Programa reconhece que o debate sobre as temáticas do meio ambiente e do desenvolvimento, inerentes à vida em sociedade, é complexo. Ele pressupõe que o conceito de meio ambiente deve considerar a natureza na relação com os seres humanos, e o de desenvolvimento evidenciar a questão ambiental como parte do processo de desenvolvimento da sociedade (UTFPR, s/d).

Assim, a abordagem que se busca no Programa é interdisciplinar, entendida, de acordo com Raynaut (2004), como um processo de diálogo entre disciplinas que possuem sua identidade teórica e metodológica, mas que apresentam limites porque fazem um recorte e apresentam um caráter parcial da realidade sobre a qual operam.

Além de ser criado no contexto que exige a interdisciplinaridade, o PPGDR está se desenvolvendo numa sociedade globalizada que exige das universidades reflexões que vão além das questões locais. Em seus estudos, Stallivieri (2002) aponta que as universidades possuem o desafio de repensarem o seu papel diante da sociedade, como instituições que abrigam a multiplicidade de valores e de opiniões e que 
Atos de Pesquisa em Educação - ISSN 1809-0354

Blumenau - vol. 11, n. 2, p.353-373 ago./nov. 2016

DOI: http://dx.doi.org/10.7867/1809-0354.2016v11n2p353-373

enfatizam o caráter universal do conhecimento. Assim, a mobilidade de estudantes, professores e pesquisadores intensificam os laços transnacionais, estabelecendo conexões e criando redes de saber universal.

As redes de cooperação formadas pelas universidades aproximam as comunidades científicas de diferentes partes do planeta, reforçando a premissa de que é no seio da universidade que devem ocorrer os grandes avanços científicos e tecnológicos e a efetiva integração dos povos, respeitando, acima de tudo, as diferenças e as especificidades de cada nação (STALLIVIERI, 2002, p. 1).

Como parte integrante desse processo, o PPGDR se depara com a necessidade de refletir sobre a sua trajetória e de pensar caminhos para a internacionalização. Portanto, este artigo tem por objetivo refletir sobre o caminho seguido pelo PPGDR em direção à internacionalização e compreender desafios para sua efetivação. O estudo tomou como referência a pesquisa documental a partir dos currículos (lattes) dos professores permanentes do Programa. Para tanto, foram analisados: a formação dos professores e as publicações de artigos em periódicos. Também foram identificados os estudantes estrangeiros matriculados no Programa desde sua criação.

A reflexão está organizada em duas partes. A primeira apresenta um panorama geral da internacionalização da Educação Superior, buscando compreender a pósgraduação; enquanto a segunda aborda a trajetória do PPGDR em direção à internacionalização, tendo como foco as atividades de pesquisa e a mobilidade de estudantes e professores.

\section{A INTERNACIONALIZAÇÃO DA PÓS-GRADUAÇÃO}

Internacionalização da Educação Superior, na qual a pós-graduação está inserida, é tratada aqui, de acordo com Morosini (2006), como atitudes sistemáticas que tenham como objetivo tornar a Educação Superior mais respondente às exigências e desafios relacionados à globalização da sociedade.

As conferências regionais e mundiais realizadas para debater a Educação Superior consideram a internacionalização como uma necessidade. Tal fato se percebe na Declaração da Conferência Regional de Educação Superior na América Latina e no Caribe (CRES), realizada de 4 a 6 de junho de 2008, na cidade de 
Atos de Pesquisa em Educação - ISSN 1809-0354

Blumenau - vol. 11, n. 2, p.353-373 ago./nov. 2016

DOI: http://dx.doi.org/10.7867/1809-0354.2016v11n2p353-373

Cartagena de Índias, Colômbia. Esta declaração aborda a questão da internacionalização e afirma que é fundamental a construção de um espaço regional de Educação Superior e, por isso, deve tomar parte da agenda dos governos e dos organismos multilaterais. E, no plano internacional, a declaração afirma que é preciso fortalecer a cooperação da América Latina e do Caribe com as outras regiões do mundo, particularmente a cooperação Sul-Sul e, dentro desta, com os países africanos.

A Declaração Mundial sobre Educação Superior no século XXI, realizada em Paris no ano de 1998, abordou a questão enfatizando que é preciso compartilhar conhecimentos teóricos e práticos entre países e continentes. Em 2009, a Conferência Mundial realizada em Paris também enfatizou que as instituições de educação superior têm a responsabilidade de ajudar no desenvolvimento, por meio da transferência de conhecimentos, cruzando fronteiras, especialmente nos países subdesenvolvidos.

Knight (2004) afirma que a internacionalização da Educação Superior apresenta diferentes dimensões. A primeira dimensão está ligada as atividades de cunho internacional que contemplam: mobilidade de docentes e discentes; relações, parcerias e projetos; programas acadêmicos de graduação, mestrado e doutorado; e iniciativas de pesquisa. A segunda dimensão está relacionada ao provimento de educação superior para outros países por meio de novos arranjos (extensão de campus, franquias e educação à distância); a terceira diz respeito à inclusão de uma dimensão intercultural ou global no currículo e no processo de ensino/aprendizagem. A quarta dimensão é relacionada ao desenvolvimento de projetos internacionais, com ênfase na Educação Superior como negócio.

Portanto, a internacionalização da Educação Superior é baseada em relações entre nações e suas instituições e sempre esteve presente nas instituições de Ensino Superior devido a seu próprio objeto - o conhecimento.

Morosini (2006) ressalta que tradicionalmente a cooperação internacional informal e o intercâmbio entre professores e alunos sempre estiveram presentes, mas o modelo de internacionalização posto atualmente leva as instituições de Ensino Superior a assumirem-na como política, planejando-a e executando-a sistematicamente. 
Atos de Pesquisa em Educação - ISSN 1809-0354

Blumenau - vol. 11, n. 2, p.353-373 ago./nov. 2016

DOI: http://dx.doi.org/10.7867/1809-0354.2016v11n2p353-373

As instituições de Ensino Superior têm o compromisso de produzir conhecimento e, considerando o caráter mundial da aquisição do saber, isto conduz a um acelerado processo de internacionalização do Ensino Superior.

No cenário que se apresenta cada vez mais multicultural e internacional, com rápidas mudanças, as instituições de Ensino Superior buscam a cooperação internacional porque, de acordo com Stallivieri (2002), reconhecem que esse é o caminho por meio do qual elas obterão o apoio necessário para o desenvolvimento do ensino, da pesquisa e da extensão, além do incremento de competência no desenvolvimento de sua missão social.

Ou seja, a internacionalização passa a ser um objetivo comum das sociedades científicas mundiais, pois, através dela, assegura-se a qualidade na renovação e na socialização do conhecimento produzido.

No Brasil as oportunidades têm crescido de forma exponencial; um número crescente de estudantes viaja para o exterior a fim de realizarem parte de cursos de graduação e pós-graduação. Da mesma forma, pesquisadores e docentes vão a outro país para desenvolverem projetos de investigação em parceria com instituições estrangeiras e atuarem em programas de graduação e pós-graduação.

A internacionalização da Educação Superior, entre outros fatores, é consequência da crescente interdependência dos países e também da necessidade de se pensar a complexidade da realidade. Raynaut (2011) lembra que a antropização crescente do mundo material faz surgir novos objeto de estudos, levanta novos desafios teóricos, metodológicos, práticos e conceituais. Nesse sentido, as teorias científicas têm sempre um caráter provisório; cada teoria alimenta sua própria destruição e cria as condições para que surjam novas teorias que a tornem questionável.

Uma interação circular vai assim estabelecendo-se entre: as ciências e as técnicas como espaços de surgimento de novos conceitos, novos paradigmas; desejos e projetos dos indivíduos e das sociedades que dispõem de meios sempre mais eficientes para torná-los realidade; e, enfim, as próprias reações não previstas, inesperadas, dos sistemas físico-naturais modificados, que fazem emergir novas questões, novos desafios à ciência, às técnicas e às sociedades (RAYNAUT, 2011, p.72).

A internacionalização está na pauta das instituições de Ensino Superior para, de um lado, atender as demandas que surgem a partir da globalização e da 
Atos de Pesquisa em Educação - ISSN 1809-0354

Blumenau - vol. 11, n. 2, p.353-373 ago./nov. 2016

DOI: http://dx.doi.org/10.7867/1809-0354.2016v11n2p353-373

complexidade e, de outro, por conta do processo avaliativo que estas instituições vêm passando.

Ou seja, quando os cursos de graduação e programas de pós-graduação são avaliados pela CAPES vários são os critérios estabelecidos e o critério da internacionalização coloca-se como fundamental.

Com relação aos critérios de avaliação, Rubin e Almeida (2011) apontam que estes estão centrados principalmente em questões referentes à proposta do programa, ao corpo docente e discente, às teses e dissertações, à produção intelectual e inserção social.

Além disso, os autores afirmam que é possível perceber que maior parte dos quesitos são avaliados de forma predominantemente quantitativa. Porém, o quesito inserção social apresenta-se mais qualitativo porque destaca informações sobre inserção e impacto regional e/ou nacional dos programas, integração e cooperação com outros programas e desenvolvimento profissional relacionados à área de conhecimento do programa.

Dias Sobrinho (2004) afirma que há uma forte disputa entre duas práticas de avaliação decorrentes de diferenças ideológicas relativas ao papel social da Educação Superior. De acordo com o autor, a Educação Superior pode ser considerada uma instituição que produz conhecimentos e forma cidadãos para as práticas da vida social e econômica, em benefício da construção de nações livres e desenvolvidas. Ou, opostamente, a Educação Superior pode ser vista como função da economia e dos interesses individuais e privados.

De acordo com uma ou outra concepção,

A avaliação instrumentaliza as reformas educacionais, produzindo mudanças nos currículos, na gestão, nas estruturas de poder, nas configurações gerais do sistema educativo, nas concepções e prioridades da pesquisa, nas noções de responsabilidade social (DIAS SOBRINHO, 2004, p. 707).

Ou seja, a avaliação impulsiona as transformações não somente para a Educação Superior propriamente dita, mas para a sociedade que se quer construir. Portanto, as instituições de Ensino Superior também podem investir na internacionalização como uma forma de melhorar seu desempenho e contribuir para tais transformações. 
Atos de Pesquisa em Educação - ISSN 1809-0354

Blumenau - vol. 11, n. 2, p.353-373 ago./nov. 2016

DOI: http://dx.doi.org/10.7867/1809-0354.2016v11n2p353-373

Morosini (2006) alerta para as diferentes formas de conceber o processo de internacionalização; ela pode ser concentrada na perspectiva liberalista se considerarmos a exportação de oportunidades e na perspectiva protecionista quando consideramos a importação. Quando a internacionalização enfatiza mais a interação entre culturas e menos a homogeneização de culturas, pode minimizar os danos da educação transnacional.

A autora também caracteriza os modelos de internacionalização como periférico e central e afirma que o caso brasileiro se insere no modelo periférico porque ele:

Se caracteriza pela presença da internacionalização universitária em alguns setores da instituição e/ou em algumas IES [Instituições de Ensino Superior]... A IDES [internacionalização da Educação Superior] está localizada junto às atividades de pesquisa e, neste caso elas ocorrem junto aos programas de pós-graduação stricto sensu. Suas estratégias têm como marca a cooperação internacional (intercâmbio de alunos e professores, convênios) (MOROSINI, 2006, p. 193).

Para justificar que o Brasil se insere no modelo periférico, alguns dados são significativos: poucas instituições de Ensino Superior são universidades, o número de bolsistas/ano no exterior é muito pequeno, o destino dos cursos dos bolsistas no exterior é concentrada na região norte do mundo, a concentração também ocorre segundo a área de conhecimento do bolsista que está exterior, a formação de recursos humanos se dá no exterior em nível de doutorado (MOROSINI, 2006).

Segundo dados do INEP (2012), o Censo de 2012 demonstrou que apenas 8\% das instituições de nível superior é universidade, ou seja, possui como função a pesquisa e o desenvolvimento da pós-graduação. Portanto, a presença da internalização é maior nessas instituições. O Quadro 1 apresenta o número de Instituições de Ensino Superior brasileiras por localização.

Quadro1: Instituições de Ensino Superior brasileiras por localização, de acordo com o Censo de 2012

\begin{tabular}{|l|c|c|c|c|}
\hline \multirow{2}{*}{ INSTITUIÇÕES } & \multicolumn{2}{|c|}{ LOCALIZAÇÃO } & \multirow{2}{*}{$\begin{array}{c}\text { NÚMERO } \\
\text { TOTAL }\end{array}$} & $\%$ \\
\cline { 2 - 3 } & CAPITAL & INTERIOR & & \\
\hline Universidades & 88 & 105 & 193 & 8,0 \\
\hline Centros Universitários & 56 & 83 & 139 & 5,8 \\
\hline Faculdades & 672 & 1372 & 2044 & 84,6 \\
\hline IF e CEFET & 30 & 10 & 40 & 1,6 \\
\hline
\end{tabular}


Atos de Pesquisa em Educação - ISSN 1809-0354

Blumenau - vol. 11, n. 2, p.353-373 ago./nov. 2016

DOI: http://dx.doi.org/10.7867/1809-0354.2016v11n2p353-373

\begin{tabular}{|c|}
\hline TOTAL \\
\hline Fonte: INEP/MEC (2012).
\end{tabular}

O Quadro 1 mostra que a grande maioria das Instituições de Ensino Superior no Brasil são Faculdades (84,6\%). Apenas 8\% são Universidades, 5,8\% são Centros Universitários e $1,6 \%$ são Institutos Federais e Centros Federais de Educação Tecnológica. O Quadro 1 também demonstra que o Ensino Superior está se desenvolvendo no sentido de interiorizar a oferta, fazendo com que jovens, que antes tinham como um sonho longínquo, possam estudar no exterior.

O interior possui 1570 Instituições de Ensino Superior, sendo 105 Universidades, 83 Centros Universitários, 1372 Faculdades e 10 Institutos Federais e Centros Federais de Educação Tecnológica, enquanto as capitais possuem 846 Instituições, sendo 88 Universidades, 56 Centros Universitários, 672 Faculdades e 30 Institutos Federais e Centros Federais de Educação Tecnológica.

Sobre o número de bolsistas/ano no exterior, a CAPES (2011) nos mostra os seguintes dados, referentes ao ano de 2011 :

Quadro 2: Distribuição de bolsistas brasileiros no exterior em 2011

\begin{tabular}{|l|r|}
\hline \multicolumn{1}{|c|}{ Nível de Estudo } & Número \\
\hline Graduação Sanduíche & 2446 \\
\hline Mestrado Pleno & 0 \\
\hline Mestrado Sanduíche & 56 \\
\hline Doutorado Pleno & 514 \\
\hline Doutorado Sanduíche & 2308 \\
\hline Pós-doc & 853 \\
\hline Estágio Sênior & 160 \\
\hline Professor Visitante no Exterior & 24 \\
\hline & 6361 \\
\hline
\end{tabular}

Fonte: CAPES, (2013)

O Quadro 2 nos mostra um grande número de estudantes da graduação, 2446, com bolsa no exterior. Isso se deve a implantação do programa Ciência sem Fronteiras pelo MEC em 2011, que tem como objetivo "promover a consolidação, expansão e internacionalização da ciência e tecnologia, da inovação e da competitividade brasileira por meio do intercâmbio e da mobilidade internacional" (CIÊNCIA SEM FRONTEIRAS, s/d). 
Atos de Pesquisa em Educação - ISSN 1809-0354

Blumenau - vol. 11, n. 2, p.353-373 ago./nov. 2016

DOI: http://dx.doi.org/10.7867/1809-0354.2016v11n2p353-373

Porém, a maioria dos estudantes vai ao exterior buscando um alto nível de formação, expressa no doutoramento e no pós-doc. O Quadro 2 mostra que há 2308 bolsas no exterior para doutorado sanduíche, 514 para doutorado pleno e 853 para pós-doc. Percebe-se, portanto, que a capacitação em nível de especialização e de mestrado não é, atualmente, o principal objetivo brasileiro. O Quadro 2 mostra apenas 56 bolsas para mestrado sanduíche no exterior. Morosini (2006) atribui esses dados ao fato de que a formação de recursos humanos em nível de doutorado abre a possibilidade do Brasil implantar seus próprios programas de pós-graduação e formar as suas gerações de cientistas.

Embora significativo, o número de estudantes no exterior é baixo se considerarmos que há no Brasil, de acordo com o INEP (2012), 378.938 professores no Ensino Superior, sendo que 107 destes ainda não possuem a graduação completa e 12.161 possuem somente a graduação.

Sobre o destino dos bolsistas, percebe-se uma concentração em três principais destinos: Estados Unidos, Portugal e França. O primeiro recebe 1673 bolsistas; o segundo, 994 e o terceiro, 1716 bolsistas. A concentração também ocorre segundo a área de conhecimento do bolsista que estuda no exterior, como mostra o gráfico 1.

Gráfico 1 - Distribuição de bolsistas no exterior por área de conhecimento

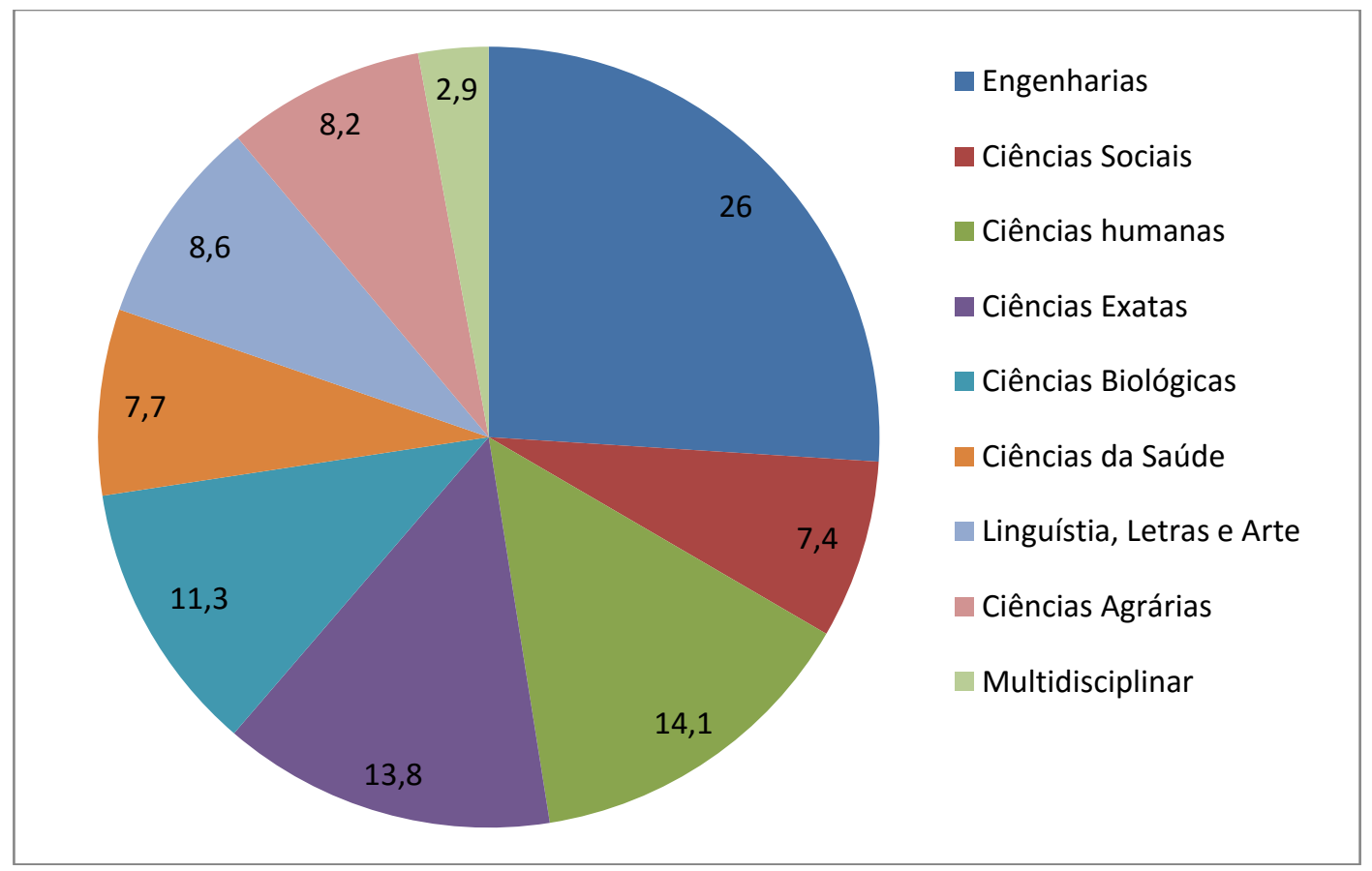

Fonte: CAPES, 2011 
Atos de Pesquisa em Educação - ISSN 1809-0354

Blumenau - vol. 11, n. 2, p.353-373 ago./nov. 2016

DOI: http://dx.doi.org/10.7867/1809-0354.2016v11n2p353-373

As quatro áreas que mais aparecem são: Engenharias (26\%), Ciências Humanas (14,1\%), Ciências Exatas (13,8\%) e Ciências Biológicas (11,3\%). Aqui chama a atenção que apenas $2,9 \%$ dos estudantes são das áreas multidisciplinares.

A partir dos dados analisados, pode-se perceber que as instituições de Ensino Superior no Brasil estão pautadas no modelo descrito por Morosini (2006) como periférico, mas está caminhando para um modelo central, onde a instituição como um todo se foca nas relações internacionais.

Por isso, os debates e as reflexões sobre internacionalização são constantes no meio acadêmico. É preciso dar a devida importância ao modelo de internacionalização universitária que vem se consolidando de forma acelerada nos países do primeiro mundo que têm nos países periféricos a sua maior demanda. A abertura para a internacionalização é chave para fortalecer o Ensino Superior. Como afirma Laus e Morosini (2005), as políticas voltadas à internacionalização podem diversificar e fortalecer a base científica e tecnológica de desenvolvimento sustentável enquanto se preservam interesses nacionais.

\section{A INTERNACIONALIZAÇÃo NO PROGRAMA DE PÓS-GRADUAÇÃo EM DESENVOLVIMENTO REGIONAL}

Nas análises realizadas pode-se perceber que a trajetória da internacionalização no Programa de Pós-Graduação em Desenvolvimento Regional se dá, sobretudo, a partir de três elementos: mobilidade docente, mobilidade discente e publicações em periódicos com projeção internacional.

Quanto ao corpo docente, o Programa possui dezesseis professores permanentes que trabalham em três linhas de pesquisa: a) Ambiente $e$ Sustentabilidade com possui oito professores permanentes, b) Regionalidade e Desenvolvimento com quatro professores permanentes e c) Educação e Desenvolvimento com quatro professores permanentes (UTFPR, s/d).

Oito, dentre os dezesseis professores do Programa, estudaram no exterior, evidenciando uma das dimensões da internacionalização apresentada por Knight (2004): a mobilidade dos docentes, conforme mostra o Quadro 3. 
Atos de Pesquisa em Educação - ISSN 1809-0354

Blumenau - vol. 11, n. 2, p.353-373 ago./nov. 2016

DOI: http://dx.doi.org/10.7867/1809-0354.2016v11n2p353-373

Quadro 3 - Professores do PPGDR, por linha de pesquisa, que estudaram no exterior

\begin{tabular}{|c|c|c|c|}
\hline $\begin{array}{l}\text { LINHA DE } \\
\text { PESQUISA }\end{array}$ & $\begin{array}{l}\text { № DE } \\
\text { PROFES- } \\
\text { SORES }\end{array}$ & CURSO & $\begin{array}{l}\text { DESTINO } \\
\text { (país) }\end{array}$ \\
\hline \multirow{2}{*}{$\begin{array}{c}\text { Educação e } \\
\text { Desenvolvimento }\end{array}$} & 1 & $\begin{array}{l}\text { Doutorado sanduíche em Conservatoire National dês } \\
\text { Arts et Metiers }\end{array}$ & França \\
\hline & 1 & $\begin{array}{l}\text { Participação em Visiting Scholar no Center for the } \\
\text { Study of Higher Education na University of Arizona }\end{array}$ & $\begin{array}{l}\text { Estados } \\
\text { Unidos }\end{array}$ \\
\hline \multirow{3}{*}{$\begin{array}{l}\text { Ambiente e } \\
\text { Sustentabilidade }\end{array}$} & 1 & Pós-Doutorado na University of California, Berkeley. & $\begin{array}{l}\text { Estados } \\
\text { Unidos }\end{array}$ \\
\hline & 1 & Pós-Doutorado na Université Blaise Pascal & França \\
\hline & 1 & $\begin{array}{l}\text { Pós-Doutorado na Université Joseph Fourrier. } \\
\text { Aperfeiçoamento em Filosofia na Université Pierre- } \\
\text { Mendès - France }\end{array}$ & França \\
\hline \multirow{3}{*}{$\begin{array}{l}\text { Regionalidade e } \\
\text { Desenvolvimento }\end{array}$} & 1 & $\begin{array}{l}\text { Doutorado sanduíche em University of South } \\
\text { Australia. } \\
\text { Mestrado em Ciências de Administração e Estudo de } \\
\text { Políticas Públicas na } \\
\text { Universidade de Tsukuba. }\end{array}$ & $\begin{array}{l}\text { Austrália } \\
\text { e } \\
\text { Japão }\end{array}$ \\
\hline & 1 & $\begin{array}{l}\text { Pós-Doutorado no Centre National Recherche } \\
\text { Scientifique - Ladyss. }\end{array}$ & França \\
\hline & 1 & $\begin{array}{l}\text { Doutorado sanduíche em Institute of Development } \\
\text { Studies }\end{array}$ & $\begin{array}{l}\text { Reino } \\
\text { Unido }\end{array}$ \\
\hline
\end{tabular}

Fonte: Plataforma Lattes (CNPq, s/d).

O Quadro 3 mostra que 50\% dos professores do Programa estudaram no exterior, sendo que o maior destino foi a França com quatro professores, seguido dos Estados Unidos, com três professores e Austrália e Japão com um professor.

Percebe-se, também, que os estudos que os professores realizaram no exterior foram em nível de pós-graduação. Um professor fez mestrado e doutorado com período sanduíche, três professores fizeram somente doutorado com período sanduíche, um professor fez aperfeiçoamento e pós-doutorado e três professores fizeram somente pós-doutorado.

No que se refere ao corpo discente, desde o início do Programa, nenhum aluno regular realizou estudos no exterior. Porém, o Programa recebeu três alunos estrangeiros no ano de 2012. Estes alunos são da Guiné Bissau e estavam inscritos no Programa de Estudantes-Convênio de Pós-Graduação (PEC-PG). Este Programa pretende possibilitar a vinda ao Brasil de cidadãos oriundos de países em desenvolvimento para realização de estudos de pós-graduação em instituições brasileiras, em nível de Mestrado e Doutorado. O principal objetivo é contribuir para fornecer a capacitação necessária para que o estudante contribua para o desenvolvimento de seu país de origem (CAPES, s/d). 
Atos de Pesquisa em Educação - ISSN 1809-0354

Blumenau - vol. 11, n. 2, p.353-373 ago./nov. 2016

DOI: http://dx.doi.org/10.7867/1809-0354.2016v11n2p353-373

Quanto às publicações em periódicos com projeção internacional, a análise feita partiu da classificação dos periódicos apresentada no Documento de Área Planejamento Urbano e Regional/Demografia, que é a área em que o PPGDR está inserido. O Quadro 4 apresenta as principais características dos periódicos de acordo com sua classificação.

Quadro 4- Principais Características dos Periódicos de acordo com sua classificação

\begin{tabular}{|c|c|}
\hline ESTRATO & CARACTERÍSTICAS \\
\hline A1 & $\begin{array}{l}\text { Periódicos científicos indexados na base JCR Social Sciences e SJR/Scopus } \\
\text { que são reconhecidos como vinculados à Área, sem consideração de seus } \\
\text { fatores de impacto. }\end{array}$ \\
\hline A2 & $\begin{array}{l}\text { Periódicos científicos indexados na base SciELO, publicado por instituição com } \\
\text { pós-graduação Stricto Sensu de âmbito nacional ou internacional reconhecida } \\
\text { pela Coordenação de Área e uma projeção internacional indicada por publicação } \\
\text { de artigos de autores de instituições estrangeiras. Deve conter artigos de autores } \\
\text { doutores, vinculados a diferentes instituições e com expressiva publicação de } \\
\text { artigos de autores e coautores filiados a instituições estrangeiras }\end{array}$ \\
\hline B1 & $\begin{array}{l}\text { Indexação em uma das seguintes bases: LATINDEX, REDALYC, DOAJ,CLASE } \\
\text { e com composição do Conselho Editorial com projeção internacional. Deve } \\
\text { conter artigos de autores doutores, vinculados a diferentes instituições e com } \\
\text { expressiva publicação de artigos de autores e coautores filiados a instituições } \\
\text { estrangeiras. }\end{array}$ \\
\hline B2 & $\begin{array}{l}\text { Indexação em uma das seguintes bases: LATINDEX, REDALYC, DOAJ,CLASE } \\
\text { e com composição nacional do Conselho Editorial. Deve conter artigos cujos } \\
\text { autores doutores estejam vinculados a instituições diferentes com concentração } \\
\text { do vínculo institucional entre } 15 \text { e } 20 \% \text {. }\end{array}$ \\
\hline B3 & $\begin{array}{l}\text { Periódico científico publicado por instituição com pós-graduação Stricto Sensu } \\
\text { reconhecida pela Coordenação de Área e com composição regional do } \\
\text { Conselho Editorial. Deve conter artigos cujos autores doutores estejam } \\
\text { vinculados a instituições diferentes com concentração do vínculo institucional } \\
\text { entre } 20 \text { e } 30 \% \text {. }\end{array}$ \\
\hline B4 & $\begin{array}{l}\text { A concentração da filiação institucional de autores se situa entre } 30 \text { e } 40 \% \text { e a } \\
\text { pertinência à área de Planejamento Urbano e Regional e Demografia é limitada. }\end{array}$ \\
\hline B5 & $\begin{array}{l}\text { Periódicos que atenderam aos critérios mínimos exigidos para um periódico } \\
\text { científico, mas não atendem às exigências adicionais descritas nos estratos } \\
\text { subsequentes. }\end{array}$ \\
\hline C & $\begin{array}{l}\text { Periódicos de outra natureza e impróprios, que não atendem aos critérios } \\
\text { mínimos do Documento de Área para serem classificados como científicos e } \\
\text { aqueles inacessíveis para avaliação. }\end{array}$ \\
\hline
\end{tabular}

Fonte: Documento de Área (CAPES, 2013).

O Quadro 4 mostra que os periódicos classificados como A1, A2 e B1 podem ser considerados com projeção internacional porque são de relevância para a área e possuem publicação de artigos de autores de instituições estrangeiras e artigos de autores doutores, vinculados a diferentes instituições e com expressiva publicação de artigos de autores e co-autores filiados a instituições estrangeiras. 
Atos de Pesquisa em Educação - ISSN 1809-0354

Blumenau - vol. 11, n. 2, p.353-373 ago./nov. 2016

DOI: http://dx.doi.org/10.7867/1809-0354.2016v11n2p353-373

Os periódicos classificados como B2, B3 e B4 possuem apenas projeção nacional, pois os autores estão vinculados a instituições diferentes, porém não são de instituições estrangeiras. Os periódicos B5 e $\mathrm{C}$ não atendem às exigências descritas nos estratos anteriores, não atendem aos critérios mínimos exigidos pela Área ou estão inacessíveis para avaliação, portanto, também não são considerados de projeção internacional.

Partindo, portanto, dessa classificação, o corpo docente permanente do PPGDR apresenta a seguinte situação no que se refere à publicação de artigos em periódicos, considerando a área de avaliação da CAPES Planejamento Urbano e Regional/Demografia:

Quadro 5 - Publicações do corpo docente do PPGDR, considerando a área de avaliação Planejamento Urbano e Regional/Demografia

\begin{tabular}{|l|c|c|c|c|c|c|c|c|c|c|}
\cline { 2 - 9 } \multicolumn{1}{c|}{} & \multicolumn{9}{|c|}{ ESTRATOS } \\
\cline { 2 - 9 } & A1 & A2 & B1 & B2 & B3 & B4 & B5 & C & N.A. & TOTAL \\
\hline $\begin{array}{l}\text { № DE } \\
\text { PUBLICAÇÕES }\end{array}$ & 14 & 37 & 21 & 34 & 10 & 14 & 05 & 58 & 118 & 311 \\
\hline
\end{tabular}

*Não avaliado pela área de Planejamento Urbano e Regional/Demografia

Fonte: Plataforma Lattes (CNPq, s/d)

A Quadro5mostra que a maior parte das publicações, 37,9\%, é feita em periódicos não avaliados pela área de Planejamento Urbano e Regional/Demografia. Considerando apenas os periódicos de projeção internacional (A1, A2 e B1), os dados mostram que $23,2 \%$ das publicações são feitas nestes periódicos. Somam $18,6 \%$ as publicações feitas nos periódicos classificados como B2, B3 e B4 e 20,3\% das publicações são feitas em periódicos de pouca relevância ou que não atendem aos critérios mínimos do Documento de Área para serem classificados como científicos e aqueles inacessíveis para avaliação.

É importante ressaltar que o corpo docente do Programa é bastante heterogêneo devido a sua natureza interdisciplinar. O corpo docente permanente é composto por titulados nas seguintes áreas: Meio Ambiente - 1; Educação - 3; Química - 1; Linguística Aplicada - 1; Química Inorgânica - 1; Engenharia Florestal - 1; Agronomia - 2; Ciência do Solo - 1; Geologia - 1; Zoologia -1; Desenvolvimento Rural -1; Administração - 1; Tecnologia e Desenvolvimento Regional - 1. 
Atos de Pesquisa em Educação - ISSN 1809-0354

Blumenau - vol. 11, n. 2, p.353-373 ago./nov. 2016

DOI: http://dx.doi.org/10.7867/1809-0354.2016v11n2p353-373

Essa diversidade de formação implica em enfoques diferenciados nas pesquisas realizadas e, por isso, os docentes enviam seus artigos para periódicos que, muitas vezes, não são avaliados pela área de Planejamento Urbano e Regional/Demografia. A tabela 5 mostra a avaliação que os periódicos em que foram publicados artigos dos docentes do Programa recebem na área em que melhor se destacam.

Quadro 6 - Publicações do corpo docente do PPGDR, considerando a área de avaliação em que melhor se destacam

\begin{tabular}{|c|c|c|c|c|c|c|c|c|c|}
\hline & \multicolumn{8}{|c|}{ ESTRATOS } & \multirow[b]{2}{*}{ TOTAL } \\
\hline & A1 & A2 & B1 & B2 & B3 & B4 & B5 & C & \\
\hline $\begin{array}{r}\text { № DE } \\
\text { PUBLICAÇÕES } \\
\end{array}$ & 34 & 56 & 40 & 51 & 31 & 80 & 15 & 04 & 311 \\
\hline
\end{tabular}

Fonte: Plataforma Lattes (CNPq, s/d)

O Quadro 6 mostra que, quando não se considera a área de avaliação Planejamento Urbano e Regional/Demografia, e, sim, a área em que o periódico é melhor avaliado, as publicações dos docentes do Programa apresentam outro panorama. Os dados mostram que $41,8 \%$ das publicações são feitas em periódicos de projeção internacional, $52,1 \%$ das publicações foram feitas em periódicos classificados como B2, B3 e B4 e apenas $6,1 \%$ das publicações foram feitas em periódicos de pouca relevância.

Ou seja, os dados mostram que o corpo docente, na área de Planejamento Urbano e Regional/Demografia apresenta uma trajetória pequena, em relação ao total de artigos publicados, em direção à internacionalização quando se analisa as publicações em periódicos com projeção internacional. Porém, o corpo docente apresentaria uma caminhada maior se a Área de Planejamento Urbano e Regional/Demografia da CAPES avaliasse os periódicos que os docentes enviam suas produções.

Os dados coletados no que se refere à formação, as publicações de artigos completos em periódicos e à matrícula de estudantes estrangeiros no Programa demonstram baixo nível de internacionalização no Programa. Esta questão já foi percebida pelo corpo docente do PPGDR e abordada na Proposta do Programa (UTFPR, 2013). 
Atos de Pesquisa em Educação - ISSN 1809-0354

Blumenau - vol. 11, n. 2, p.353-373 ago./nov. 2016

DOI: http://dx.doi.org/10.7867/1809-0354.2016v11n2p353-373

A Proposta do PPGDR apresenta pontos que o Programa precisa melhorar e, entre eles, destaca-se: falta publicação em periódicos do qualis da Área de Planejamento Urbano e Regional, falta uma estratégia de publicação para o corpo docente, demasiadas publicações fora do qualis da área, são poucos os convênios nacionais e internacionais (UTFPR, 2013).

Estes pontos demonstram uma preocupação com a internacionalização do PPGDR como uma ferramenta a serviço da formação de docentes, pesquisadores e discentes, permitindo a realização de experiências complementares ao processo educacional no âmbito da pós-graduação. De acordo com Marrara (2007), o processo de internacionalização com fins acadêmicos, tem como objetivo contribuir com o desenvolvimento da educação e da ciência, através da colaboração e da troca de experiências com agentes estrangeiros.

A universidade se internacionalizaria, portanto, pela sua capacidade de colaborar para o desenvolvimento científico em nível supranacional seja pelas suas atividades de formação, seja pela qualidade e impacto de sua pesquisa (MARRARA, 2007).

Diante dos pontos que precisam ser melhorados, o corpo docente do PPGDR estabeleceu quatro grandes objetivos, dos quais, destacam-se dois: elevar a nota do Programa para 4; elevar a influência do PPGDR interna e externamente (UTFPR, 2013).

Para atingir tais objetivos, a Proposta do Programa (UTFPR, 2013) estabelece ações, dentre as quais se destacam as seguintes:

- Aumentar a produção do Programa mediante publicação em periódicos relevantes para a Área de Planejamento Urbano e Regional/Demografia (qualis B2, no mínimo).

- Prospectar e agilizar o estabelecimento de convênios com instituições nacionais e estrangeiras.

- Ampliar a integração com outros programas, prioritariamente da Área de Planejamento Urbano e Regional/Demografia, visando composição de bancas, intercâmbios acadêmicos, realização recíproca de palestras.

- Aumentar a filiação dos docentes em sociedades científicas. 
Atos de Pesquisa em Educação - ISSN 1809-0354

Blumenau - vol. 11, n. 2, p.353-373 ago./nov. 2016

DOI: http://dx.doi.org/10.7867/1809-0354.2016v11n2p353-373

- Prospectar e divulgar eventos relevantes para a Área de Planejamento Urbano e Regional / Demografia, visando a participação de docentes com trabalhos completos.

- Propor mesas em eventos relevantes para a Área de Planejamento Urbano e Regional/Demografia.

- Participar e propor/liderar projetos em parcerias com outras instituições estratégicas.

As ações apresentadas na proposta do Programa estão voltadas para a melhoria da qualidade do ensino ofertado, pois os objetivos de elevar a nota do Programa e sua influência interna e externa, passam automaticamente pelo trabalho com o conhecimento e a dedicação à pesquisa. Goergen (2012) lembra que toda instituição de Ensino Superior que queira desempenhar com competência atarefa de formar as novas gerações nos campos do ensino e da pesquisa deve necessariamente fazê-lo na perspectiva de um mundo globalizado, mas sem esquecer que o conhecimento e a educação devem ter sempre um sentido de humanização, democratização e mudança social.

Também é importante ressaltar que trilhar um caminho rumo à internacionalização implica em reconhecer que esta é atrelada a padronização de currículos, conhecimentos, conteúdos e avaliação, imposta externamente e que, dentro desta lógica, a ideia do local torna-se subjugada a imposições externas e descontextualizadas (RUBIN; FRANCO, 2012).

Enfim, refletir sobre os desafios da internacionalização num programa de pósgraduação requer considerar as peculiaridades do espaço local, especialmente num programa que tem como área de concentração o desenvolvimento regional sustentável. A auto avaliação que o PPGDR faz, neste sentido, apresenta-se como um caminho viável para o reconhecimento de suas fragilidades e a proposição de objetivos a serem atingidos visando, além da internacionalização, a reflexão sobre a produção do conhecimento científico.

\section{CONSIDERAÇÕES FINAIS}


Atos de Pesquisa em Educação - ISSN 1809-0354

Blumenau - vol. 11, n. 2, p.353-373 ago./nov. 2016

DOI: http://dx.doi.org/10.7867/1809-0354.2016v11n2p353-373

Este texto teve por objetivo refletir sobre o caminho seguido pelo Programa de Pós-Graduação em Desenvolvimento Regional da Universidade Tecnológica Federal do Paraná - Campus Pato Branco em direção à internacionalização e compreender desafios para sua efetivação.

A Internacionalização do Ensino Superior deve ser vista pelo prisma da Globalização, pois é baseada nas relações entre nações e suas instituições. Tradicionalmente a cooperação internacional informal e o intercâmbio entre professores e alunos sempre estiveram presentes nas instituições de Ensino Superior devido ser o conhecimento o seu objeto. Ou seja, as instituições de Ensino Superior têm o compromisso de produzir conhecimento e, considerando o caráter mundial da aquisição do saber, isso demanda um processo de internacionalização do Ensino Superior.

Porém, o modelo de internacionalização posto atualmente leva as instituições de Ensino Superior a assumirem-na como política, planejando-a e executando-a sistematicamente. O Brasil demonstra fazer parte do modelo periférico de internacionalização devido aos índices que apresenta em relação às instituições de Ensino Superior (em sua maioria não são universidades), o número de bolsistas/ano no exterior, o destino dos cursos dos bolsistas no exterior, a área de conhecimento do bolsista que está exterior, a formação de recursos humanos que se dá no exterior.

Seguindo a mesma tendência, encontra-se o PPGDR que apresenta um baixo grau de internacionalização de acordo com os dados analisados referentes a formação dos docentes e suas publicações em periódicos e a mobilidades estudantil.

Os dados sugerem que o Programa continue investindo na auto avaliação como ferramenta indispensável para reconhecimento dos seus pontos fortes e de suas fragilidades e no trabalho efetivo para que os objetivos elencados na sua Proposta sejam efetivados.

Neste contexto, importa sempre refletir sobre que internacionalização se busca: aquela para somente atender as exigências das avaliações externas ou aquela entendida como uma estratégia para aprimorar a qualidade do ensino e da pesquisa. Mais do que uma tentativa de aumentar os índices que podem fazer do PPGDR um programa com projeção internacional, é preciso um exercício de repensar seus 
Atos de Pesquisa em Educação - ISSN 1809-0354

Blumenau - vol. 11, n. 2, p.353-373 ago./nov. 2016

DOI: http://dx.doi.org/10.7867/1809-0354.2016v11n2p353-373

objetivos, no intuito de melhorar a qualidade de seu ensino e das pesquisas desenvolvidas em seu âmbito.

\section{LUCIANE MARIA SERRER DE MATTOS}

Pedagoga, Mestre em Desenvolvimento Regional pela Universidade Tecnológica Federal do Paraná (UTFPR).

\section{MARLIZE RUBIN OLIVEIRA}

Doutora em Educação pela Universidade Federal do Rio Grande do Sul. Docente do Programa de Pós-Graduação em Desenvolvimento Regional da Universidade Tecnológica Federal do Paraná (UTFPR).

\section{REFERÊNCIAS}

CAPES. Coordenação de Aperfeiçoamento de Pessoal de Nível Superior. Documento de Área 2009. Disponível em:

<http://www.capes.gov.br/images/stories/download/avaliacao/PLANURB_23un10.pdf >. Acesso em: 10 nov. 2013.

CAPES. Geo-Capes: dados estatísticos. Indicadores 2011. Disponível em: <http://www.capes.gov.br/estatisticas>. Acesso em: 14 nov. 2013.

CAPES. Comunicado n.002/2012 - Área de Planejamento Urbano e Regional/Demografia. Brasília, 26 de Junho de 2012. Disponível em: <http://www.capes.gov.br/images/stories/download/avaliacao/Interdisciplinaridade_PI anejamento_Urbano.pdf>. Acesso em: 12 nov. 2013.

CAPES. Documento de Área 2013. Disponível em: <http://www.capes.gov.br/component/content/article/44-avaliacao/4680planejamento-urbano-e-regionaldemografias. Acesso em: 10 nov. 2013.

CAPES. Programa de Estudantes-Convênio de Pós-Graduação: Objetivo. Disponível em: <http://www.capes.gov.br/cooperacao-internacional/multinacional/pec-pg>. Acesso em 20 nov. 2013.

CIÊNCIA SEM FRONTEIRAS. Programa Ciência sem Fronteiras: o que é. Disponível em: <http://www.cienciasemfronteiras.gov.br/web/csf/o-programa>. Acesso em: 18 nov. 2013.

CNPq. Conselho Nacional de Desenvolvimento Científico e Tecnológico. Plataforma Lattes. Disponível em: <http://lattes.cnpq.br/>.Acesso em: 21 nov. 2013.

DIAS SOBRINHO, J. Avaliação Ética e Política em Função da Educação como Direito Público ou como Mercadoria? Educ. Soc. vol. 25, n. 88, Campinas, out, 2004, p. 703-725. 
Atos de Pesquisa em Educação - ISSN 1809-0354

Blumenau - vol. 11, n. 2, p.353-373 ago./nov. 2016

DOI: http://dx.doi.org/10.7867/1809-0354.2016v11n2p353-373

GOERGEN, P. A Internacionalização dos Programas de Pós-graduação. Revista Espaço Pedagógico. v. 19, n. 2, Passo Fundo, jul./dez. 2012, p. 247-257.

INEP. Instituto Nacional de Estudos e Pesquisas Educacionais Anísio Teixeira. Censo da Educação Superior: Resumo Técnico, 2012. Disponível em: <http://download.inep.gov.br/download/superior/censo/2012/resumo_tecnico_censo_ educacao_superior_2012.pdf>. Acesso em: 15 nov. 2013.

KNIGHT, J. Internationalization remodeled: definition, approaches, and rationales. Journal of Studies in International Education. v. 8. n.1. Bethesda, 2004, p. 5-31.

LAUS, S. P.; MOROSINI, M. C. Internationalization of higher education in Brazil. In: WIT, H. de; et al (ed.) Higher Education in Latin America: the international dimension. The World Bank: Washington, 2005. p. 111-147.

MARRARA, T. Internacionalização da Pós-Graduação: objetivos, formas e avaliação. Revista Brasileira de Pós Graduação. v. 4, n. 8. Brasília, dez. 2007, p. 245-262.

MOROSINI, M. C. Internacionalização da Educação Superior: um modelo em construção? In: AUDY, J. L. N.; MOROSINI, M, C. (orgs.) Inovação e Empreendedorismo na Universidade. Porto Alegre: EDIPUCRS, 2006, p.189-210.

RAYNAUT, C. Interdisciplinaridade: mundo contemporâneo, complexidade e desafios à produção e à aplicação de conhecimentos. In. PHILIPPI Jr., A.; NETO, A. J. S. (Editores). Interdisciplinaridade em ciência, tecnologia \& inovação. Barueri: Manole, 2011, p. 69-105.

RAYNAUT, C. Meio Ambiente e Desenvolvimento: construindo um novo campo do saber a partir da perspectiva ambiental. Desenvolvimento e Meio Ambiente, n. 10, p. 21-32, jul./dez. 2004.

RUBIN, M.; ALMEIDA, J. Programas de pós-graduação interdisciplinares: contexto, contradições e limites do processo de avaliação Capes. Revista Brasileira de PósGraduação. v. 8, n. 15, Brasília, mar. de 2011, p. 37 - 57.

RUBIN, M.; FRANCO, M. E. D. P. Do Internacional ao Local: desafios da pósgraduação no Brasil. In: 35aㅡ REUNIÃO ANUAL ANPED - EDUCAÇÃO, CULTURA, PESQUISA E PROJETOS DE DESENVOLVIMENTO: O BRASIL DO SÉCULO XXI. GT 11. Porto de Galinhas, 2012. Disponível em: <http://35reuniao.anped.org.br/trabalhos/113-gt11>. Acesso em: 06 dez. 2013.

RUBIN, M.; GRIKE, F. Produção de Conhecimento: uma análise no Programa de Pós-Graduação em Desenvolvimento Regional da UTFPR Câmpus Pato Branco. 2012. 
Atos de Pesquisa em Educação - ISSN 1809-0354

Blumenau - vol. 11, n. 2, p.353-373 ago./nov. 2016

DOI: http://dx.doi.org/10.7867/1809-0354.2016v11n2p353-373

STALLIVIERI, L. O Processo de Internacionalização nas Instituições de Ensino Superior. Revista do Conselho de Reitores das Universidades Brasileiras. Brasília, 2002.

UTFPR. Universidade Tecnológica Federal do Paraná. Programa de Pós-graduação em Desenvolvimento Regional. Disponível em:

<http://www.utfpr.edu.br/patobranco/estrutura-universitaria/diretorias/dirppg/posgraduacao/mestrados/ppgdr2/pagina-inicial>. Acesso em: 20 nov. 2013.

UTFPR. Programa de Pós-graduação em Desenvolvimento Regional: Proposta do Programa, 2013. Disponível em:

$<$ https://sucupira.capes.gov.br/sucupira/public/consultas/coleta/propostaPrograma/lis taProposta.jsf>. Acesso em: 01 jun. 2016

Artigo recebido em agosto de 2015.

Aprovado em abril de 2016.

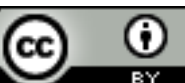

Este trabalho está licenciado com uma Licença Creative Commons - Atribuição 4.0 Internacional 